Nevşehir Bilim ve Teknoloji Dergisi Cilt 4(1) 97-107 2015

DOI: 10.17100/nevbiltek.210928

URL: http://dx.doi.org/10.17100/nevbiltek.210928

\title{
Avrupa Birliği Üyesi Ülkelerin Refah Düzeyini Etkileyen Faktörler: Path Analizi
} Yaklaşımı

\author{
Gamze Özel ${ }^{1, *}$, İlker Altun ${ }^{1}$ \\ ${ }^{1}$ Hacettepe Üniversitesi, Fen Fakültesi, İstatistik Bölümü, Ankara
}

$\ddot{O} z$

Avrupa Birliği (AB), 1957 yılında kurulan, günümüzde 28 üye ülkeden oluşan ve toprakları büyük ölçüde Avrupa kıtasında bulunan siyasi ve ekonomik bir örgütlenmedir. AB üyeleri arasındaki istikrar oldukça önemlidir. Bu nedenle AB’ye üye ülkelerin ekonomik ve parasal birliğe katılabilmeleri için gerekli şartları içeren Maastricht Anlaşmasında, üye ülkelerin ekonomileri arasındaki farklılıkların giderilebilmesi için bazı kriterler tespit edilmiştir. Bu çalışmanın amacı, Maastricht kriterlerini de dikkate alarak, AB üyesi ülkelerin refah düzeylerine etki eden faktörleri incelemektir. Gayri safi yurt içi hasıla (GSYH) değişkeninin AB ülkelerindeki refah seviyesini gösteren bir unsur olduğu düşünülmüştür. Bu amaçla, ülkelerin GSYH değerlerine etki edebilecek birbirleri ile ilişkili değişkenler arasındaki ilişkileri kapsayan Path Analizi kullanılmıştır. Klasik regresyon analizi ve korelasyon analizinin yetersiz kaldığı durumlarda Path analizi ile değişkenler arasındaki doğrudan ilişkilerin yanı sıra dolaylı ilişkilerin varlığı da incelenebilir. Böylece, 2013 yılına ait Eurostat'tan elde edilen istihdam, işsizlik, ithalat, ihracat oranlarının ve borç stoku, toplam gelir, doğrudan yatırım, insani gelişme endeksi, enflasyon faktörlerinin GSYH üzerindeki doğrudan ve dolaylı etkileri incelenmiştir.

Anahtar Kelimeler: Avrupa Birliği, path analizi, enflasyon, gayri safi yurt içi hasıla

The Affecting Factors of Welfare Level for the European Union Countries: A Path Analysis Approach

\begin{abstract}
The European Union (EU) is a politic-economic union of 28 member states that are primarily located in Europe. The EU operates through a system of supranational independent institutions and intergovernmental negotiated decisions by the member states. Stability among EU member is extremely important. Hence, the Maastricht Treaty set out convergence and stability criteria that had to be met before a country could become a member of the EU. The aim of this study is to investigate factors affecting welfare levels of EU countries as regard to Maastricht Criteria. Gross domestic product is considered to show welfare level of EU countries. For this aim, path analysis is used which shows variables related with each other and effective on GDP. Hence, direct and indirect influences of employment, unemployment, imports, exports and debt ratios, total income, direct investment, human development index, consumer price inflation factors on GDP are investigated.
\end{abstract}

Keywords: European Union (EU), path analysis, inflation, gross domestic product

*e-mail: gamzeozl@hacettepe.edu.tr 


\section{Giriş}

AB, 1957 yılında kurulan, günümüzde yirmi yedi üye ülkeden oluşan ve toprakları büyük ölçüde Avrupa kıtasında bulunan siyasi ve ekonomik bir örgütlenmedir [1]. 1992 yılında, Avrupa Birliği Antlaşması olarak da bilinen Maastricht Antlaşması'nın yürürlüğe girmesi sonucu, var olan Avrupa Ekonomik Topluluğu'na yeni görev ve sorumluluk alanları yüklenmesiyle kurulmuştur [2]. AB, günümüze dek altı genişleme geçirerek 28 üyeli, 457 milyondan fazla insanı barındıran büyük bir birlik haline gelmiştir. AB'nin kuruluşundan itibaren başarılı bir gelişim göstermesi, başlangıçta topluluğa üye olmak istemeyen ülkelerin de daha sonra üyelik başvurusunda bulunmalarına neden olmuştur. AB, halen genişleme kapısını üyelik için siyasi ve ekonomik kriterleri yerine getirebilecek herhangi Avrupa ülkesine açık tutmaktadır. Ancak, AB'ye tam üyelik başvurusunda bulunan adayların Maastricht Anlaşması ve Kopenhag kriterlerini sağlaması gerekmektedir. Maastricht Anlaşması, AB’ye üye ülkelerin ekonomik ve parasal birliğge katılabilmeleri için gerekli şartları, Kopenhag kriterleri ise AB'ye tam üyelik koşullarının esaslarını belirlemektedir [3].

AB’nin genişleme sürecinin üyeleri üzerindeki etkileri Baldwin vd. [4], Breuss [5], Doyle ve Fidrmuc [6] tarafından incelenmiştir. Brada ve Kutan [7] tarafından aday ülkelerin ekonomik performanslarının AB'ye üyelik süreci üzerinde etkisi olduğu belirtilmiştir. Nicoladies [8] tarafından yeni üyelerin $\mathrm{AB}$ 'de etkin olabilmeleri için dikkate almaları gereken ekonomik faktörler üzerinde durmuştur. Barysch [9], beşinci genişlemenin $\mathrm{AB}$ üzerinde olumlu etkisi olduğunu ancak yeni üye olan ülkelerin ekonomik durumları orta seviyede olduğu için bu genişlemenin önemsiz olduğunu belirtmiştir. Oktay ve Özer'in [10] çalışmasında $\mathrm{AB}$ ülkelerinin genişleme öncesi ve sonrası seçilen sosyal ve ekonomik göstergeleri arasındaki ilişki tespit edilmiştir. AB'ye üye ülkeler ile Türkiye’nin karşılaştırılması ile ilgili bir çalışma da Filiz ve Çemrek [11] tarafından yapılmıştır. Hendrickx [12], altıncı genişlemede Bulgaristan ve Romanya'nın AB'ye katılımının önemli olduğu ancak her iki ülkenin de AB'de etkin üyeler olabilmesi için yardıma ihtiyaç duyabilecekleri sonucuna ulaşılmıştır. Romanya'nın Batı Balkan Ülkeleri, Moldova, Ukrayna ve Karadeniz arasında önemli bir coğrafi konuma sahip olması nedeniyle AB üzerinde olumlu etkisi olduğu Dragan [13] tarafından belirtilmiştir. Bu çalışmalar AB'ye aday ülkelerin kurum ve makroekonomik politikalarını AB'nin aradığı koşullara uygun hale getirmelerinin gerekliliğini göstermektedir. AB'nin genişleme sürecinin etkileri üzerine birçok çalışma yapılmasına rağmen aday AB’ye üyelik sürecine etki eden değişkenler arasındaki ilişkilerin bulunması üzerine herhangi bir çalışma bulunmamaktadır. Bu çalışmanın temel amacı, AB ülkelerinin gelişmişlik düzeyi üzerinde etkili olduğu düşünülen faktörlerin ne kadarının gelişmişlik düzeyi üzerinde anlamlı olduğunu belirleyip, anlamlı bulunan değişkenlerin etkilerini direkt ve dolaylı etkiler olarak ayrı ayrı ifade etmektir. Bu nedenle, çalışmada Maastricht kriterleri dikkate alınarak, AB'ye üye ülkelerin GSYH değerlerinin refah seviyelerini gösterdiği düşünülmüştür. Bu fikirden yola çıkarak GSYH üzerinde istihdam, işsizlik, ithalat, ihracat oranlarının ve borç stoku, toplam gelir, doğrudan yatırım, insani gelişme endeksi, enflasyon faktörlerinin doğrudan ve dolaylı etkileri ile incelenmiştir. Korelasyon analizi sadece değişkenler arasındaki ilişkinin önem düzeyini belirlerken, Path analizi bu ilişkileri doğrudan ve dolaylı etkileri ile birlikte inceleme fırsatı vermektedir. Çalışmada Eurostat’tan elde edilen AB'ye üye 28 ülkeye ait 2013 yılı verileri kullanılmıştır. 


\section{Materyal ve Metot}

\subsection{Materyal}

$\mathrm{Bu}$ çalışmada kullanılan veriler Eurostat web sayfasından alınmıştır [14]. AB ülkelerinin istihdam, işsizlik, ithalat, ihracat oranlarının ve borç stoku, toplam gelir, doğrudan yatırım, insani gelişme endeksi, enflasyon değişkenlerinin AB üyesi ülkelerin GSYH üzerindeki doğrudan ve dolaylı etkilerini incelemek için 28 üye ülkeye ait 2013 yılı Eurostat verileri LISREL paket programı ile değerlendirilmiştir. AB'ye üye ülkelerin tam üyelik başvuru, müzakere başlangıç ve üyelik tarihleri Tablo 1'de verilmiştir:

Tablo 1. Çalışmada kullanılan ülkelerin tam üyelik başvuru, müzakere başlangıç ve üyelik tarihleri

\begin{tabular}{|c|c|c|c|}
\hline Ülke & Tam Üyelik Başvuru Tarihi & Müzakere Başlangıç Tarihi & Üyelik Tarihi \\
\hline Belçika & Kurucu & - & 25.03 .1957 \\
\hline Çek Cumhuriyeti & 01.01.1996 & 01.03.1998 & 01.05.2004 \\
\hline Danimarka & 01.05.1967 & 01.06.1970 & 01.01 .1973 \\
\hline Almanya & Kurucu & - & 25.03.1957 \\
\hline Estonya & 01.11.1995 & 01.03.1998 & 01.05 .2004 \\
\hline Yunanistan & 01.06.1975 & 01.07.1976 & 01.01.1981 \\
\hline İspanya & 01.07.1977 & 01.02.1979 & 01.01.1986 \\
\hline Fransa & Kurucu & - & 25.03.1957 \\
\hline İrlanda & 01.05.1967 & 01.06.1970 & 01.01 .1973 \\
\hline İtalya & Kurucu & - & 25.03.1957 \\
\hline Kibris & 01.07.1990 & 01.03.1998 & 01.05 .2004 \\
\hline Letonya & 01.10.1995 & 01.02 .2000 & 01.05 .2004 \\
\hline Litvanya & 01.10.1995 & 01.02 .2000 & 01.05 .2004 \\
\hline Lüksemburg & Kurucu & - & 25.03 .1957 \\
\hline Macaristan & 01.03.1994 & 01.03.1998 & 01.05.2004 \\
\hline Malta & 01.07.1990 & 01.02 .2000 & 01.05 .2004 \\
\hline Hollanda & Kurucu & - & 25.03.1957 \\
\hline Avusturya & 17.07.1989 & 01.02.1993 & 01.01.1995 \\
\hline Polonya & 01.04.1994 & 01.03.1998 & 01.05.2004 \\
\hline Portekiz & 01.05.1978 & 01.11.1978 & 01.01.1986 \\
\hline Slovenya & 01.06.1996 & 01.03.1998 & 01.05.2004 \\
\hline Slovakya & 01.06.1995 & 01.02 .2000 & 01.05.2004 \\
\hline Finlandiya & 18.03.1992 & 01.02.1993 & 01.01.1995 \\
\hline İsveç & 01.07.1991 & 01.02.1993 & 01.01.1995 \\
\hline İngiltere & 01.05.1967 & 01.06.1970 & 01.01.1973 \\
\hline Bulgaristan & 14.12.1995 & 01.02 .2000 & 01.01 .2007 \\
\hline Romanya & 22.06.1995 & 01.02 .2000 & 01.01.2007 \\
\hline Hirvatistan & 21.02 .2003 & 03.10 .2005 & 01.07.2013 \\
\hline
\end{tabular}


Özel G., Altun İ.

\subsection{Metot}

İki dağılımın karşılıklı değiş̧imleri incelendiğinde terimlerindeki değişiklikler bakımından bir benzerlik veya bağlılık varsa, dağılımların ilgili oldukları olaylar arasında bir ilişkinin bulunduğu söylenebilir. Örneğin herhangi bir malın fiyatı yükselirken arzı da artıyor veya talebi azalıyorsa, insanlarda boy uzunluğu ile birlikte ağırlık da yükseliyorsa, söz konusu değişkenler arasında ilişki var demektir. İncelenen iki değişken arasındaki ilişki çoğu zaman bir sebep-sonuç ilişkisidir. Üzerinde çalışılan konu ile ilgili olan değişkenler arasındaki bu ilişkiler de genel olarak doğrusal ve doğrusal olmayan ilişkiler olarak iki grupta incelenmektedir. Değişkenler arasında ilişki varsa bu ilişkinin derecesi ve fonksiyonel şekli belirlenmeye çalışılmaktadır. İki ya da daha çok değişken arasındaki ilişsinin matematiksel işlevle gösterilebilmesi regresyon analizi ile mümkündür. Bu değişkenler arasındaki ilişkinin yönünün ve derecesinin araştırılması ise korelasyon analizinin konusudur. Değişkenler arasındaki doğrusal ilişkinin derecesi için ölçü, korelasyon katsayısı olarak bilinmektedir. Herhangi iki değişken arasında tam bir ilişki ve değişim aynı yönde olduğunda korelasyon katsayısı 1 olacaktır. Benzer bir biçimde tam bir ilişki, fakat değişkenler için zıt yönde bir değişim söz konusu olduğunda korelasyon katsayısı -1 değerini alacaktır. İki değişken arasında kısmi bir ilişki varsa da korelasyon katsayısı -1 ile +1 arasında değişen değerler alacaktır. İki değişken arasında hiçbir ilişki olmadığında ise korelasyon katsayısı sıfır değerini alacaktır. Bu bakış açısıyla değişkenlerden biri sebep, diğeri de bu sebebin sonucu olarak ele alındığında, korelasyon katsayısı, bunların birbiri üzerine ne derecede etkili olabildiklerini de gösteren bir ölçüdür. Ancak yine de bu, iki değişken arasındaki ilişkinin tam olarak belirlenebilmesi için yeterli değildir. Örneğin bir değişken diğeri ile yüksek korelasyon halinde ise bu ilişki her ikisinin üçüncü bir değişkenle korelasyon halinde bulunmasından ileri geliyor olabilir. Bu nedenle iki değişken arasındaki korelâsyonu, ele alınan diğer değişkenler sabit durumda iken hesaplamak gerekebilir. Bu şekilde hesaplanan korelasyon katsayılarına kısmi korelasyon katsayıları denilmektedir. Ancak korelasyon katsayısı ve kısmi korelasyon katsayısı ele aldığımız değişkenler arasındaki ilişkiyi bir sebep-sonuç ilişkisi şeklinde vermez. Değişsenler arasında sebep-sonuç ilişkisi olup olmadığı araştırılıyorsa ve sonucu etkileyen değişkenler arasındaki direkt ve dolaylı etkilerin birlikte incelenmesi söz konusu ise, bu durumda kullanılacak ölçüt ne korelasyon katsayıları, ne de kısmi korelasyon katsayılarıdır. Çoklu regresyon analizinde ise, her bir bağımsız değişkenin bağımlı değişken üzerine doğrudan etkisi söz konusudur. Ancak bazı durumlarda, bağımlı değişken ile bağımsız değişken ya da değişkenler arasındaki doğrudan ilişkilerin yanı sıra dolaylı ilişkilerin varlığı da söz konusu olabilir. Bu durumda klasik regresyon analizi ve korelasyon analizi yetersiz kalmaktadır [15].

Korelasyon analizinin ve regresyon analizinin yetersiz kaldığı bu durumlar, Path analizi adı verilen istatistiksel tekniğin ortaya çıkmasına neden olmuştur. Path analizinde amaç, değişken grupları arasındaki nedensel ilişkilerin önemliliğini ve büyüklüğünü tahmin etmektir. Çoklu regresyon analizinde dikkate alınan varsayımlar altında, bir bağımlı değişken tüm bağımsız değişkenler üzerinden analiz edilirken, Path analizinde her bağımlı değişken her bir bağımsız değişken üzerinden analiz edilmekte yani birden fazla regresyon analizi yapılabilmektedir. İki değişken arasındaki sebep-sonuç ilişkisinde, hangi değişkenin ya da değişkenlerin sebep değişkeni, hangi değişkenin ya da değişkenlerin ise sonuç değişkeni olarak ele alınması gerektiği önemli bir konu olduğundan, bu ilişkinin araştırıcı tarafından belirlenip analizin de buna göre yapılması gerekmektedir. Wright'in geliştirdiği Path analizi yöntemi, yalnızca 
sebep-sonuç değişkenleri arasındaki ilişkiler dizisine uygulanmaktadır. Path analizini Path diyagramı ve Path katsayılarına dayanarak incelemek mümkündür.

Path diyagramı bağımsız ve bağımlı değişkenler arasındaki ilişkileri şematik olarak ifade etmeye yarayan bir araçtır. Değişkenler arasında sebep-sonuç ilişkisinin olması önem arz etmektedir. Path diyagramlarında bu ilişkiler tek yönlü oklar ile gösterilir ve oklar her bir bağımsız değişkenden bağımlı değişkene doğru çizilir. Path katsayılarının sembolik veya sayısal değerleri çizilen oklar üzerine yazılır. Girdi Path diyagramı olası nedensellik ilişkilerini gösteren henüz tahmin edilmemiş temsili parametreleri ifade ederken çıktı Path diyagramı istatistiki analizin sonuçlarını ifade eder ve tahmin edilen parametre değerlerini (katsayıları) gösterir. Path diyagramında bağımsız değişkenler arasındaki korelasyon ise iki yönlü oklar ile gösterilir ve birleştirici eğri biçiminde çizilir. İki yönlü eğri biçimindeki ok durumunda ise basit korelasyon katsayılarının sembolik veya sayısal değerleri oklar üzerine yazılır.

$\mathrm{X}_{\mathrm{i}}$ bağımsız raslantı değişkenleri, u hata terimi ve $\mathrm{Y}$ bağımlı değişkeninin meydana getirdiği sebep sonuç ilişkisi,

$$
\mathrm{Y}=\mathrm{b}_{0}+\mathrm{b}_{1} \mathrm{X}_{1}+\ldots+\mathrm{b}_{\mathrm{k}} \mathrm{X}_{\mathrm{k}}+\mathrm{u}
$$

biçimindeki doğrusal regresyon modeli ile elde edilebilir. Bu modelde yer alan değişkenler arasındaki ilişkiler Şekil 1'deki Path diyagramı ile gösterilebilir:

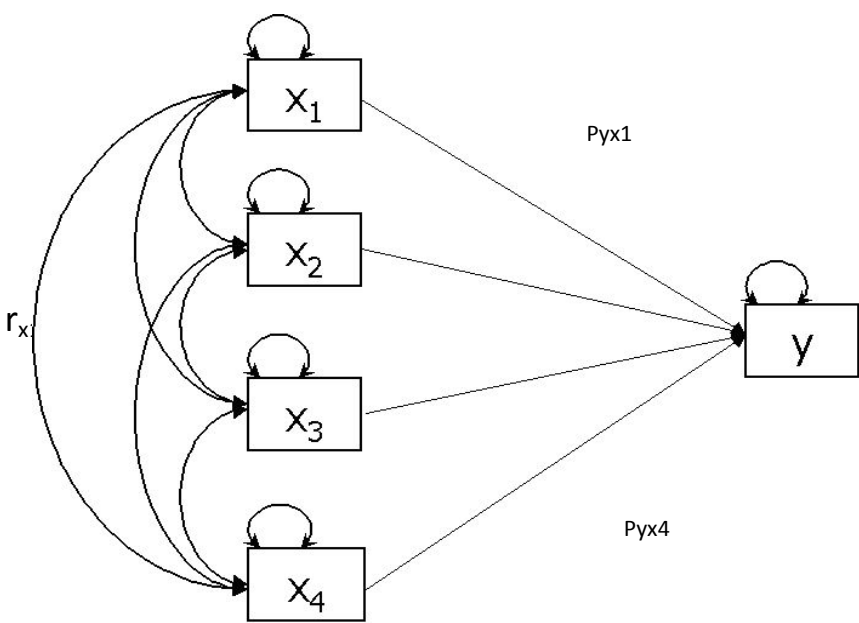

Şekil 1. Değișkenler arasındaki ilişkilerin Path diyagramı

Şekil 1'de belirtilen Path diyagramında birbiriyle ilişkili olduğu varsayılan değişkenler oklar vasıtası ile ilişkilendirilmektedir. Şekil 1'de görüldüğü gibi hem bağımlı-bağımsız hem de bağımsız değiş̧kenleri arasında bir iliş̧i söz konusudur. Sebep değişkenleri arasında korelasyon $r_{\mathrm{x}_{\mathrm{i}} \mathrm{x}_{\mathrm{j}}} \neq 0$ 'dır. Okun yönü etkinin yönünü belirlemektedir. Bağımsız değişkenler arasındaki ilişki çift yönlü ok ile gösterilmektedir. Bağımsız değişkenlerin hem bağımlı değişken üzerinde dolaysız etkisi hem de birbirleri üzerinde dolaylı etkileri mevcuttur. Her iki etki toplam etkiyi oluşturmaktadır. Toplam etki ve bileşenleri standartlaştırılmış değişkenler kullanılarak Eşitlik (1) aşağıdaki gibi yazılabilir: 


$$
Y=P_{y x 1} x_{1}+P_{y x 2} x_{2}+\ldots+P_{y x k} x_{k}+P_{y x e} x_{e}
$$

Burada, Path katsayısı $P_{y x}=\sigma_{x y} / \sigma_{y}$ biçimindedir. Buna göre, $P_{y x}$, x sebep değişkeni ile y sonuç değişkeni arasındaki Path katsayısını (dolaysız etki); $\sigma_{x y}$, x'e bağlı olarak y'de meydana gelen değişimi ve $\sigma_{y}$, sebep değişkenlerine bağlı olarak y’ e gözlenen değişim miktarını göstermektedir. Korelasyon katsayısı +1 ile -1 arasında değişirken, Path katsayıları bu sınırların dışına çıkabilmektedir. Aynı korelasyona sahip olan değişkenler arasında, farklı Path diyagramları çizilebilmekte ve bunlar arasındaki doğrusal ilişkiler farklı şekillerde yorumlanabilmektedir. Path katsayıları ve Path analizi tekniği, aynı değişkenler için farklı sebep-sonuç diyagramlarını kurup, bunları farklı şekillerde yorumlama imkânı sağlamaktadır [16].

Diyagramlar yardımıyla Path ve korelasyon katsayılarından oluşan aşağıdaki denklem serisi oluşturulmaktadır. Bu denklem çözümü ile doğrudan ve dolaylı etkiler tahmin edilmektedir:

$$
\begin{aligned}
& r_{y x 1}=P_{y x 1}+r_{x 1 \times 2} P_{y \times 2}+\ldots+r_{x 1 x k} P_{y x k}, \\
& r_{y x 2}=r_{x 2 \times 1} P_{y x 1}+P_{y x 2}+\ldots+r_{x 2 \times k} P_{y x k}, \\
& \vdots \\
& r_{y x k}=r_{x k x 1} P_{y x 1}+r_{x k x 2} P_{y x 2}+\ldots+P_{y x k} .
\end{aligned}
$$

Burada, $\mathrm{P}_{\mathrm{yx} 1}$, y üzerinde $\mathrm{x}_{1}{ }^{\prime}$ in doğrudan etkisini ve $\mathrm{r}_{\mathrm{x} 1 \times 2} \mathrm{P}_{\mathrm{yx} 2}, \mathrm{x}_{1}$ 'in $\mathrm{x}_{2}$ üzerindeki dolaylı etkisini göstermektedir. Doğrudan ve dolaylı etkilerin toplamı, $\mathrm{Y}$ ile $\mathrm{X}_{\mathrm{i}}$ değişkenleri arasındaki korelasyon katsayısını vermektedir. Değişkenler arasındaki basit korelasyon katsayıları bulunup, Eşitlik (3)'te yerine yazılırsa, $\mathrm{k}$ bilinmeyenli denklem sistemi elde edilir. Bu denklem sistemi matris formuna dönüştürülerek Path katsayıları aşağıdaki gibi hesaplanmaktadır:

$$
\left[\begin{array}{c}
P_{y x 1} \\
P_{y \times 2} \\
\cdot \\
P_{y \times k}
\end{array}\right]=\left[\begin{array}{cccc}
1 & r_{x 1 \times 2} & \cdot & r_{x 1 x k} \\
r_{x 2 \times 1} & 1 & \cdot & r_{x 2 x k} \\
\cdot & \cdot & \cdot & \cdot \\
r_{x k x 1} & r_{x k x 2} & \cdot & 1
\end{array}\right]\left[\begin{array}{c}
r_{y x 1} \\
r_{y \times 2} \\
\cdot \\
r_{y x k}
\end{array}\right], \quad P=A^{-1} B
$$

Eşitlik (4)’te bağımsız değişkenlere ait korelasyon matrisi A, Path katsayıları vektörü B ve bağımsız değişkenlerin sonuç ile olan korelasyonlarından oluşan sütun vektörü ise B ile gösterilmiştir.

\section{Bulgular}

Bağımsız değişkenlerin seçimi yapılırken değişkenlerin Kopenhag kriteri ve Maastricht Anlaşması'nda belirtilen maddelere uygun olmasına dikkat edilmiştir. Çalışmada kullanılan değişkenler Tablo 2'de sunulmuştur: 
Tablo 2. Çalışmada kullanılan değişkenlerin ortalama ve standart sapmaları

\begin{tabular}{ccc}
\hline Kullanılan Değişkenler & Ortalama & Standart Sapma \\
GSYH (Milyar Euro) & 83.5500 & 57.8860 \\
İstihdam Oranı (\%) & 0.9071 & 0.8056 \\
İşsizlik Oranı (\%) & 9.2286 & 3.9183 \\
İthalat Oranı (\%) & 61.5071 & 27.9367 \\
İhracat Oranı (\%) & 64.8786 & 34.9186 \\
Borç Stoku (\% GSYH) & 65.1429 & 34.7708 \\
Toplam Gelir (\% GSYH) & 41.9357 & 6.0836 \\
Doğrudan Yatırım Geliri (Milyar Euro) & -0.0003 & 0.0001 \\
İnsani Gelişme İndeksi & 0.8524 & 0.0615 \\
\hline Enflasyon (Tüketici Fiyatı) (\%, yıllık) & 2.7610 & 0.8791 \\
\hline
\end{tabular}

Tablo 2'de verilen değişkenler kullanılarak GSYH üzerinde etkisi olan değişkenleri tespit emek için veri kümesine Path Analizi uygulanmış ve elde edilen sonuçlar Tablo 3’te verilmiştir:

Tablo 3. Path analizi modellerine ait sonuçlar

\begin{tabular}{ccccc}
\hline Model & $\mathbf{R}$ & $\mathbf{R}^{2}$ & Düzeltilmiş $\mathbf{R}^{2}$ & St. Hata \\
1 & 0.584 & 0.34 & 0.316 & 47.87 \\
2 & 0.725 & 0.53 & 0.487 & 41.44 \\
3 & 0.847 & 0.72 & 0.681 & 32.67 \\
4 & 0.879 & 0.77 & 0.733 & 29.89 \\
5 & 0.911 & 0.83 & 0.791 & 26.45 \\
7 & 0.904 & 0.82 & 0.786 & 26.75 \\
\hline
\end{tabular}

Tablo 3 incelendiğinde, GSYH'ya etki eden değişkenleri içeren en iyi modelin 7. model olduğu görülmektedir. Modellerde yer alan bağımsız değişkenler Tablo 4'te verilmiştir:

Tablo 4. Modelde yer alan bağımsız değişkenler

\begin{tabular}{cl}
\hline Model & Modelde Yer Alan Bağımsız Değişkenler \\
$\mathbf{1}$ & Sabit Terim, İnsani gelişme endeksi \\
$\mathbf{2}$ & Sabit Terim, İnsani gelişme endeksi, İhracat \\
$\mathbf{3}$ & Sabit Terim, İnsani gelişme endeksi, İhracat, İthalat \\
$\mathbf{4}$ & Sabit Terim, İnsani gelişme endeksi, İhracat, İthalat, Doğrudan Yatırım Geliri \\
$\mathbf{5}$ & Sabit Terim, İnsani gelişme endeksi, İhracat, İthalat, Doğrudan Yatırım Geliri, Enflasyon \\
$\mathbf{6}$ & Sabit Terim, İhracat, İthalat, Doğrudan Yatırım Geliri, Enflasyon \\
$\mathbf{7}$ & Sabit Terim, İhracat, İthalat, Doğrudan Yatırım Geliri, Enflasyon, Toplam Gelir \\
\hline
\end{tabular}

Model 7'de yer alan değişkenler arasındaki Pearson ilişki katsayısı testi sonuçları Tablo 5'te verilmiştir: 
Özel G., Altun İ.

Tablo 5. Faktörlere ait Pearson ilişki katsayısı matrisi

\begin{tabular}{|c|c|c|c|c|c|c|}
\hline & $\begin{array}{c}\text { İhracat } \\
\left(\mathrm{X}_{1}\right)\end{array}$ & $\begin{array}{c}\text { Ithalat } \\
\left(\mathrm{X}_{2}\right)\end{array}$ & $\begin{array}{c}\text { Toplam Gelir } \\
\left(\mathbf{X}_{3}\right)\end{array}$ & $\begin{array}{c}\text { Doğrudan } \\
\text { Yatırım Geliri } \\
\left(\mathrm{X}_{4}\right)\end{array}$ & $\begin{array}{c}\text { Enflasyon } \\
\left(\mathrm{X}_{5}\right)\end{array}$ & $\begin{array}{c}\text { GSYH } \\
\text { (Y) }\end{array}$ \\
\hline $\begin{array}{c}\text { İhracat } \\
\left(\mathrm{X}_{1}\right)\end{array}$ & 1 & $\begin{array}{l}\mathbf{0 . 9 8 5 * *} \\
(0.000)\end{array}$ & $\begin{array}{c}-0.210 \\
(00283)\end{array}$ & $\begin{array}{l}-0.347 \\
(0.070)\end{array}$ & $\begin{array}{c}0.160 \\
(0.416)\end{array}$ & $\begin{array}{l}\mathbf{0 . 4 9 4} 4^{* *} \\
(0.008)\end{array}$ \\
\hline $\begin{array}{c}\text { İthalat } \\
\left(\mathbf{X}_{2}\right)\end{array}$ & $\begin{array}{c}\mathbf{0 . 9 8 5}^{* *} \\
(0.000)\end{array}$ & 1 & $\begin{array}{c}-0.281 \\
(00148)\end{array}$ & $\begin{array}{l}-0.343 \\
(0.074)\end{array}$ & $\begin{array}{c}0.220 \\
(0.261)\end{array}$ & $\begin{array}{l}\mathbf{0 . 3 7 8}^{*} \\
(0.048)\end{array}$ \\
\hline $\begin{array}{c}\text { Toplam Gelir } \\
\qquad\left(\mathbf{X}_{3}\right)\end{array}$ & $\begin{array}{l}-0.210 \\
(0.283)\end{array}$ & $\begin{array}{l}-0.281 \\
(0.148)\end{array}$ & 1 & $\begin{array}{c}0.327 \\
(0.090)\end{array}$ & $\begin{array}{l}-0.340 \\
(0.077)\end{array}$ & $\begin{array}{l}\mathbf{0 . 4 5 7} \\
(0.015)\end{array}$ \\
\hline $\begin{array}{c}\text { Doğrudan } \\
\text { Yatırım Geliri } \\
\left(\mathbf{X}_{4}\right)\end{array}$ & $\begin{array}{l}-0.347 \\
(0.070)\end{array}$ & $\begin{array}{l}-0.343 \\
(0.074)\end{array}$ & $\begin{array}{c}0.327 \\
(0.090)\end{array}$ & 1 & $\begin{array}{c}0.155 \\
(0.432)\end{array}$ & $\begin{array}{r}0.052 \\
(0.791)\end{array}$ \\
\hline $\begin{array}{c}\text { Enflasyon } \\
\left(\mathrm{X}_{5}\right)\end{array}$ & $\begin{array}{c}0.160 \\
(0.416)\end{array}$ & $\begin{array}{c}0.220 \\
(0.261)\end{array}$ & $\begin{array}{l}-0.340 \\
(0.077)\end{array}$ & $\begin{array}{c}0.155 \\
(0.432)\end{array}$ & 1 & $\begin{array}{l}-\mathbf{0 . 3 9 9} \\
(0.035)\end{array}$ \\
\hline $\begin{array}{c}\text { GSYH } \\
\text { (Y) }\end{array}$ & $\begin{array}{l}\mathbf{0 . 4 9 4}^{\text {** }} \\
(0.008)\end{array}$ & $\begin{array}{c}\mathbf{0 . 3 7 8}^{*} \\
(0.048)\end{array}$ & $\begin{array}{l}\mathbf{0 . 4 5 7} 7^{*} \\
(0.015)\end{array}$ & $\begin{array}{c}0.052 \\
(0.791)\end{array}$ & $\begin{array}{l}-\mathbf{0 . 3 9 9}{ }^{*} \\
(0.035)\end{array}$ & 1 \\
\hline
\end{tabular}

Tablo 5 incelendiğinde GYSH faktörünün İthalat, toplam gelir ve enflasyon değişkenlerinin GSYH ile ilişkili olduğu 0.05 yanılma düzeyinde söylenebilir. Ayrıca GSYH değişkeni ihracat değişkeni ile 0.01 yanılma düzeyinde ilişkilidir. Ancak, ithalat ile ihracat değişkeninin doğrudan ilişkili olması incelenen veri için regresyon ve korelasyon analizi yapılmasını engellemektedir. Tablo 5'te verilen korelasyon katsayıları Eşitlik (3)'te yerine yazıldığında aşağıdaki eşitlikler elde edilmiştir:

$$
\begin{aligned}
& 0.494=\mathrm{P}_{\mathrm{yx} 1}+0.985 \mathrm{P}_{\mathrm{yx} 2}-0.210 \mathrm{P}_{\mathrm{y} \times 3}-0.347 \mathrm{P}_{\mathrm{yx} 4}+0.160 \mathrm{P}_{\mathrm{yx} 5} \text {, } \\
& 0.378=0.985 \mathrm{P}_{y \times 1}+\mathrm{P}_{y \times 2}-0.281 \mathrm{P}_{\mathrm{yx} 3}-0.343 \mathrm{P}_{\mathrm{yx4}}+0.220 \mathrm{P}_{\mathrm{y} \times 5}, \\
& 0.457=-0.210 \mathrm{P}_{\mathrm{yx} 1}-0.281 \mathrm{P}_{\mathrm{yx} 2}+\mathrm{P}_{\mathrm{yx} 3}+0.327 \mathrm{P}_{\mathrm{yx} 4}-0.340 \mathrm{P}_{\mathrm{yx} 5} \text {, } \\
& 0.052=-0.347 \mathrm{P}_{\mathrm{yx} 1}-0.343 \mathrm{P}_{\mathrm{yx} 2}+0.327 \mathrm{P}_{\mathrm{yx} 3}+\mathrm{P}_{\mathrm{yx} 4}+0.155 \mathrm{P}_{\mathrm{yx} 5} \text {, } \\
& -0.399=0.160 \mathrm{P}_{\mathrm{yx} 1}+0.220 \mathrm{P}_{\mathrm{yx} 2}-0.340 \mathrm{P}_{\mathrm{yx} 3}+0.155 \mathrm{P}_{\mathrm{yx} 4}+\mathrm{P}_{\mathrm{yx} 5} .
\end{aligned}
$$

Yukarıda verilen denklem sistemi matris formuna dönüştürülerek Path katsayıları Esitlik (4)’ten yararlanarak hesaplanabilir:

$$
\mathrm{P}=\left[\begin{array}{ccccc}
1 & 0.985 & -0.210 & -0.347 & 0.160 \\
0.985 & 1 & -0.281 & -0.343 & 0.220 \\
-0.210 & -0.281 & 1 & 0.327 & -0.340 \\
-0.347 & -0.343 & 0.327 & 1 & 0.155 \\
0.160 & 0.220 & -0.340 & 0.155 & 1
\end{array}\right]^{-1}\left[\begin{array}{c}
0.494 \\
0.378 \\
0.457 \\
0.052 \\
-0.399
\end{array}\right]=\left[\begin{array}{c}
0.92 \\
1.07 \\
-0.16 \\
0.26 \\
-0.29
\end{array}\right]
$$


Tablo 5’e göre bu modelde yer alan değişkenler, ithalat, ihracat, toplam gelir, doğrudan yatırım geliri, enflasyondur. Modeldeki değişkenlere ait dolaylı ve doğrudan ilişkileri daha ayrıntılı gösteren Path diyagramı Şekil 2'de sunulmuştur:

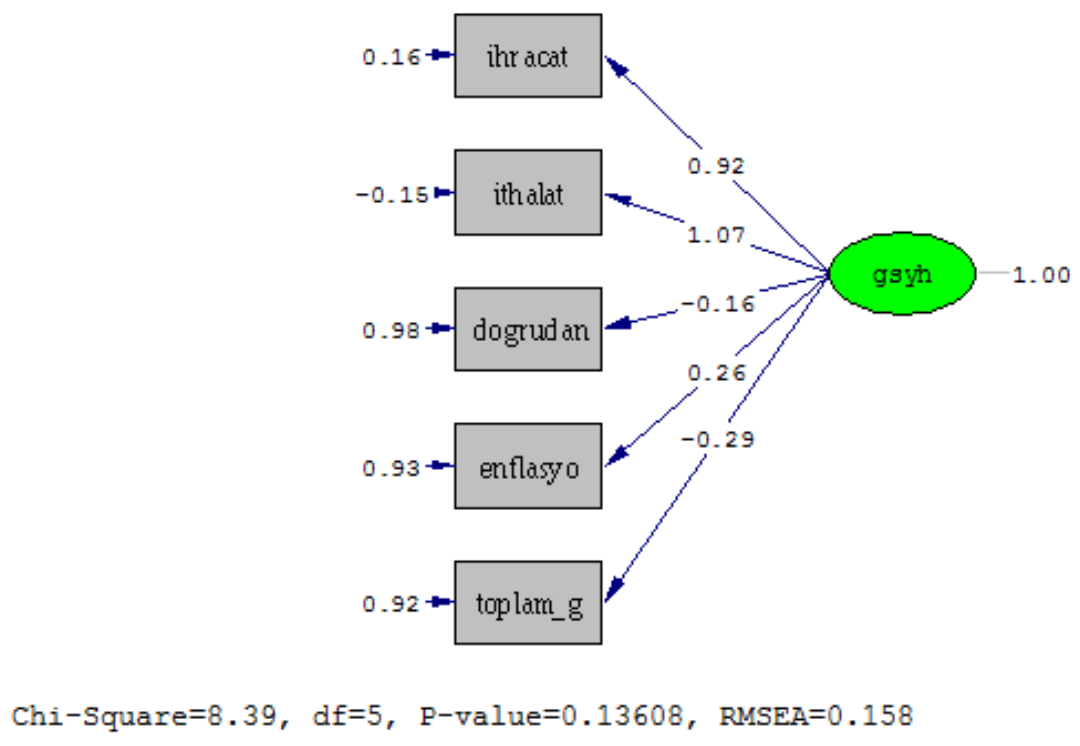

Şekil 2. Model 7'ye ait Path analiz diyagramı

Şekil 2 incelendiğinde, toplam gelir ve doğrudan yatırım geliri GSYH ile negatif yönlü bir ilişkili olduğu sonucuna ulaşııııştır. İthalat, ihracat, enflasyon GSYH ile pozitif yönde bir ilişki sergilemektedir. Şekil 2'ye göre elde edilen standartize edilmiş çoklu regresyon denklemi,

$$
\mathrm{Y}=0.92 \mathrm{x}_{1}+1.07 \mathrm{x}_{2}-0.16 \mathrm{x}_{3}+0.26 \mathrm{x}_{4}-0.29 \mathrm{x}_{5}
$$

biçimindedir. Burada Path katsayılarının etki sıralaması ithalat için 1.07; ihracat için 0.92; toplam gelir için -0.29; doğrudan yatıım geliri için -0.16; enflasyon için 0.26 biçimindedir. Bağımsız değişkenlerin her birinin bağımlı değişken üzerindeki toplam etkisi Path katsayısı (dolaysız etki) ile dolaylı etkinin toplamından oluşmaktadır. Diğer bir deyişle, toplam etki korelasyon katsayısıdır. Toplam etkinin ayrıştırılmış biçimi Tablo 6'da verilmiştir:

Tablo 6. Toplam etkinin dolaylı ve dolaysız etkilere ayrıştırılması

\begin{tabular}{lccc}
\hline & Dolaylı Etki & Dolaysız Etki & Toplam Etki \\
& & & \\
İhracat $\left(\mathbf{X}_{\mathbf{1}}\right)$ & -0.426 & 0.92 & 0.494 \\
İthalat $\left(\mathbf{X}_{\mathbf{2}}\right)$ & -0.692 & 1.07 & 0.378 \\
Toplam Gelir $\left(\mathbf{X}_{\mathbf{3}}\right)$ & 0.617 & -0.16 & 0.457 \\
Doğrudan Yatırım Geliri $\left(\mathbf{X}_{\mathbf{4}}\right)$ & -0.208 & 0.26 & 0.052 \\
Enflasyon $\left(\mathbf{X}_{\mathbf{5}}\right)$ & -0.109 & -0.29 & -0.399 \\
\hline
\end{tabular}


Tablo 5 ve 6'ya göre, en önemli etkiyi eden ithalat en az etkiyi eden değişken ise yatırım geliridir. Ayrıca ithalat değişkeninin GSYH üzerindeki dolaysız etkisi diğer değişkenlere göre en az iken, dolaysız etkisinin diğer değişkenlerden yüksek olduğu görülmektedir. Bu durum, korelasyon analizinin yalnızca toplam etki hakkında bilgi verirken, Path analizinin tüm bağımsız değişkenlerin dolaylı ve dolaysız etkilerini ayrıştırarak toplam etkinin içeriği hakkında bilgi verdiğini göstermektedir. Bu sonuçlar önceki çalışmalara da paralellik göstermektedir. Çarıkçı [17] tarafindan AB'ye üye olacak ülkelerin makroekonomik istikrar ve öngörülebilirliğin korunması için yeterli önlemlerin alınması amacıyla uygun maliye ve para politikalarının uygulanmasının önemli olduğunu sonucuna ulaşılmışırı.

\section{Tartışma ve Sonuç}

İlk kurulduğunda hedefi bir ekonomik ortak pazar yaratmak olan $\mathrm{AB}$, yeni üye kabul ederken aday ülkenin $\mathrm{AB}$ standartlarına belirli seviyede sahip olmasına ve belirtilen siyasi ve ekonomik kriterleri sağlamasına önem göstermektedir. Her geçen gün daha çok alanda ortak mevzuatın ve uygulamanın oluştuğu $\mathrm{AB}$ müktesebatının korunması ve bütünleşme sürecinde geri adım atılmaması AB'nin temel önceliğidir. Bu yüzden AB'nin gelişimine paralel olarak genişleme politikası ve üyelik koşuları da değişmiş, üyeliğin getirdiği sorumluluklar arttıkça, yeni üye olacak ülkelerin önündeki engeller yükseltilmiştir.

$\mathrm{Bu}$ çalışmada, $\mathrm{AB}$ büyüme sürecinde etkisi olabileceği düşünülen değişkenler Path Analizi ile incelenmiştir. Path Analizi ile kişi başına düşen GSYH'a etki eden 11 değişken incelediğinde modele ithalat, ihracat, toplam gelir, doğrudan yatırım geliri, enflasyon değişkenlerinin girdiği görülmektedir. Bunlardan toplam gelir ve doğrudan yatırım geliri negatif yönlü bir ilişki içindeyken geri kalan ithalat, ihracat, enflasyon pozitif yönde bir ilişki sergilemektedir. Ayrıca GSYH değişkenine en önemli etkiyi eden ithalat, en az etkiyi eden değişken ise yatırım geliri olduğu görülmektedir. Son yıllarda Yunanistan, Portekiz ve İspanya gibi ülkelerde meydana gelen makroekonomik krizler bir ülkedeki makro ekonomik dengenin $\mathrm{AB}$ için önemli olduğunu göstermiştir.

\section{Kaynaklar}

[1] Dinçer, B., Özaslan, M., Kavasoğlu, T., "Illerin ve Bölgelerin Sosya-Ekonomik Gelişmişlik Sıralaması Araştırması”, DPT Yayınları, Ankara, 2003.

[2] Tatlıdil, H., Cinel, O., “Türkiye'nin AT'ye Üyeliği ve Beşeri Kalkınma Durumu”, Hazine Dergisi, 6, 53-68, 1997.

[3] Ünvan, Y.A., Özel, G. “Avrupa Birliği'ne üyelik sürecinde etkili faktörlerin koşullu lojistik regresyon modelleri ile değerlendirilmesi”, İstanbul Üniversitesi İktisat Fakültesi Ekonometri ve İstatistik Dergisi, 14, 62-83, 2011.

[4] Baldwin, R.E., Francois, J.F., Portes, R. "The Costs and Benefits of Eastern Enlargement: The Impact on the EU and Central Europe”, Economic Policy, 24, 127-176, 1997.

[5] Breuss, F., "Benefits and Dangers of EU Enlargement”, Empirica, 29 (3), 245-274, 2002.

[6] Doyle, O. ve Fidrmuc, J., "Who Is in Favor of Enlargement? Determinants of Support for EU Membership in the Candidate Countries' Referenda”, ZEI/WDI Conference on Political Economy of Transition: Job Creation and Job Destruction, Bonn, 1-30, 2003. 
[7] Brada, J.C., Kutan, A.M. "The Convergence of Monetary Policy between Candidate Countries and the European Union”, Economic Systems, 25, 3, 215-231, 2001.

[8] Nicolaides, P., "The Application of EU Competition Rules to Services of General Economic Interest: How to Reduce Competitive Distortions: Competition Policy in Europe”, Springer Verlag, Berlin, 2003.

[9] Barysch, K., "Does Enlargement Matter for the EU Economy?”, Centre For European Reform, Policy Brief, 1-6, 2003.

[10] Oktay, E., Özer, H., "Genişlemenin Avrupa Birliğinin Bazı Sosyal ve Ekonomik Göstergeleri Arasındaki İlişkiye Etkisi”, VI. Ulusal Ekonometri ve İstatistik Sempozyumu, Gazi Üniversitesi, Ankara, 2003.

[11] Filiz, Z., Çemrek, F., “Avrupa Birliği'ne Üye Ülkeler ile Türkiye'nin Karşılaştırılması”, VII. Ulusal Ekonometri ve İstatistik Sempozyumu, İstanbul, 2005.

[12] Hendrickx, L., "From EU25 to EU27: Opportunities and Challenges Ahead for SMEs", http://www.ueapme.com/docs/press_releases/pr_2006/061221_EU27.pdf.

[13] Dragan, G., "Romania’s Accession to EU: Challenges and Opportunities”, EUIJ Workshop: EU Enlargement and Its Economic Impacts on Transitional Countries, 1-24, 2007.

[14] Eurostat, http://epp.eurostat.ec.europa.eu/portal/page/portal/statistics/search_database

[15] Şahinler, S., Görgüllü, Ö., "Path analizi ve bir uygulama”, MKÜ Ziraat Fakültesi Dergisi, 5, 87102, 2000.

[16] Kaşıkçı, D., "Path katsayısı, kısmi regresyon katsayısı ve korelasyon katsayılarının karşılaştırmalı olarak incelenmesi”, Yüksek lisans tezi, Gazi Üniversitesi, Fen Bilimleri Enstitüsü, 2000.

[17] Çarıkçı, $\quad$ E., “AB ile Müzakereler ve Beklentiler”, http://carikci.cankaya.edu.tr/publications/h2ABMB3.pdf, 2009. 